\title{
Pesticide Effect on Populations of Tetranychus urticae Koch (Acari: Tetranychidae) and a Predaceous Mite on Table Grapes in the Hex River Valley
}

\author{
A. Schwartz
}

Viticultural and Oenological Research Institute (VORI), Private Bag X5026, 7600 Stellenbosch, Republic of South Africa.

Submitted for publication: January 1990

Accepted for publication: May 1990

Key words: Tetranychus urticae, Amblyseius addoensis, red spider, phytoseiids, biocontrol, predaceous mite

\begin{abstract}
Tetranychus urticae Koch is a pest of different table grape cultivars in the Hex River Valley. Two seasonal colour forms of this mite occur. The spring and summer form is straw-coloured to light green (green form), whereas the late summer females are light red to brick-coloured (carmine form). The green form was more abundant on young leaves on which feeding caused a yellow stippling. These leaves dried out and turned brown, and young shoots became stunted. This form also caused chlorosis on mature leaves. It occurred in maximum numbers in October. The carmine form caused bronzing or chlorosis of mature leaves, with infestation peaks in February or March.

The results suggested that $T$. urticae infestations were caused by broad-spectrum insecticides, viz. organo-phosphates and synthetic pyrethroids, which were applied for the control of key pests. This was largely brought about by the destruction of the predaceous mite, Amblyseius addoensis Van der Merwe \& Ryke, an important predator of T. urticae.
\end{abstract}

The red spider mite or common red spider mite, Tetranychus cinnabarinus (Boisd.), which has been associated with table grapes for many years, was described as an unimportant pest by Swart, Barnes \& Myburgh (1976). In recent years, however, the spider mite problem on table grapes in the Hex River Valley has changed to the extent that many producers are compelled to control the mite annually with an acaricide. Along with this development the scientific standing of the mite was changed to that of Tetranychus urticae Koch (Meyer, 1987), which incorporates two colour forms. One is straw-coloured to light green, the other light red to brickcoloured. Meyer (1987) refers to the green form and the carmine form respectively. According to Botha (1989) the carmine form (previously $T$. cinnabarinus) has been a serious pest of apple-growing areas for about 40 years, whereas the green form was recorded for the first time in Ceres in 1984. The first record of the green form on table grapes dates to October 1986 (unpublished data). The unaccommodating safety periods of effective acaricides as well as high costs have prompted the present biological study in an attempt to establish a practical management control program for both colour forms of $T$. urticae. A prerequisite was to determine the factor or factors responsible for the problem of population build-up.

\section{MATERIALS AND METHODS}

The study was carried out on two table grape cultivars, viz., Vitis vinifera L. cv. Almeria on the farm Hylton and cv. Barlinka at De Vlei and VORI Experimental farm (Hex River Valley). The project lasted three seasons.

Seasonal occurrence: Sampling in the 1986/87 season commenced during October (300-mm shoot length) and was carried out every 21 days. Samples consisted of leaves taken from three positions on a shoot, viz. apical, middle and basal.
Positional leaves were kept separate to determine leaf preference. Only one shoot was sampled per plot (5 vines/plot) in each of 20 randomly chosen plots in the vineyard, for a total of 60 leaves. These leaves were cut to drop into a jar containing a $70 \%$ ethanol solution and processed according to the method of Schwartz (1987). The adults of $T$. urticae were counted together with natural enemies present in the supernatant. In addition, one bunch per vine in each plot was examined with a magnifier, from fruitset stage, for the presence of $T$. urticae.

Sampling in the 1987/88 and 1988/89 seasons started during September (bud burst) and was carried out every 14 days. Initially one new shoot, including the leaves, from a single vine for each of 10 randomly distributed plots (5 vines/plot) was sampled into a jar containing a $70 \%$ ethanol solution (for a total of 10 shoots per vineyard). As soon as the shoots with leaves had developed sufficiently $(300-\mathrm{mm}$ length), the sampling was adapted to consist of positional leaves only (total 30 ), as previously described. The subsequent processing of the samples and counting were done as described for 1986/87. In addition one bunch in each of 10 plots was examined for the presence of $T$. urticae from the time of fruitset.

The visual damage caused by both forms of $T$. urticae was described.

The effect of insecticidal spray programmes: The same vineyards and sampling procedures were used to determine the effect of spray programmes on the incidence of $T$. urticae and its predators.

The composition of the spray programmes for the three vineyards differed somewhat and comprised treatments for the control of vine mealybug, Planococcus ficus (or- 
ganophosphate insecticides); banded fruit weevil, Phlyctinus callosus (synthetic pyrethroids); fruit fly, Ceratitis rosa and Ceratitis capitata (insecticide dusting); downy mildew, Plasmopara viticola; powdery mildew, Uncinula necator; and grey mould Botrytis cinerea (fungicides). Barlinka at the VORI Experimental farm was kept free from insecticide sprays except for the compulsory fruit fly treatments, viz. two to three applications of fenthion dust. During the 1988/89 season a change was brought about in the insecticide spray programme for Almeria at Hylton, where sticky trunk bands were used as a substitute for a pyrethroid spray.

\section{RESULTS AND DISCUSSION}

\section{Seasonal occurrence}

Hylton farm: During 1986/87, T. urticae (carmine form) was first recorded at the beginning of February, reached a peak (average 5 mites/leaf) in March, and declined, to disappear at the end of April (Fig. 1A).

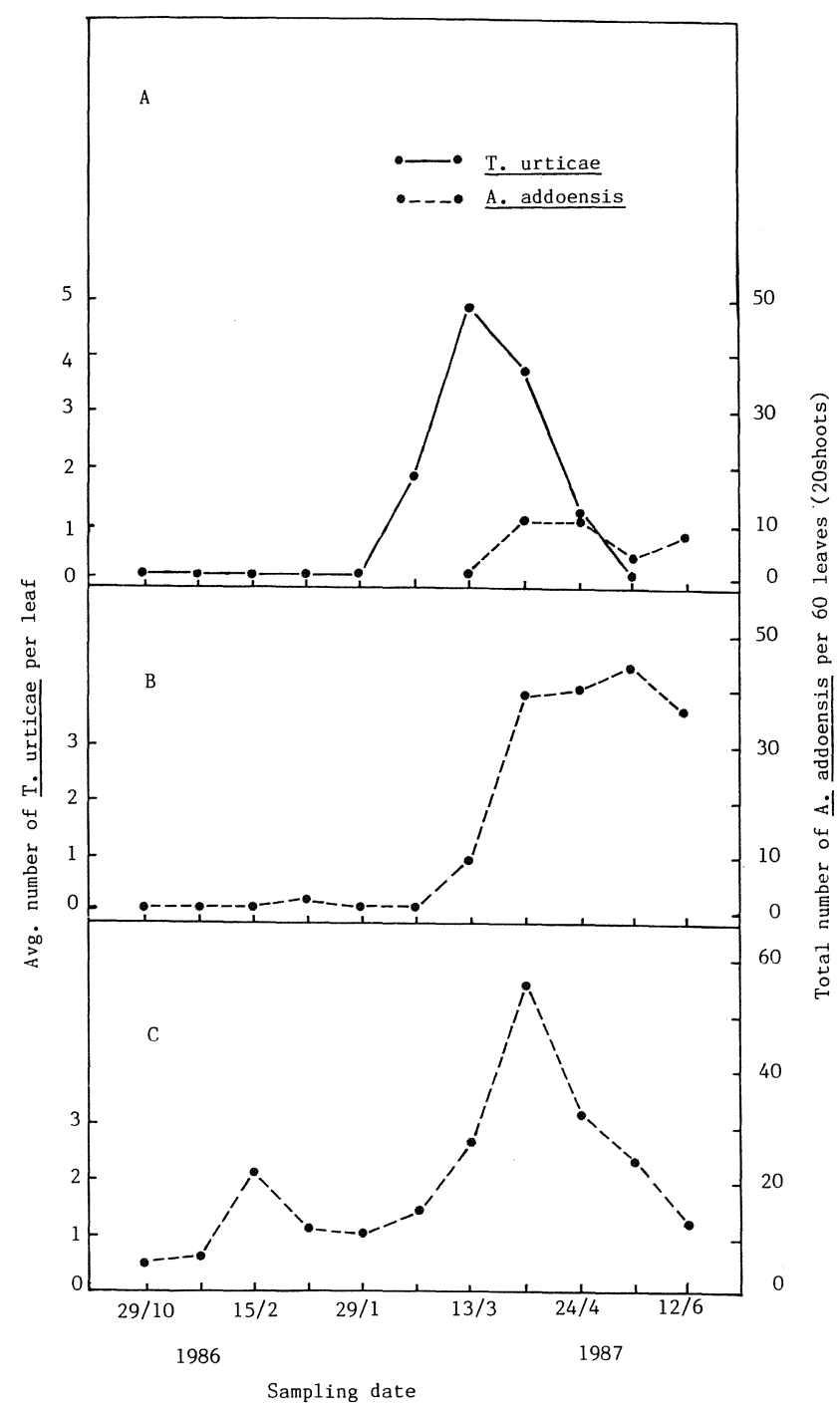

FIGURE 1

The seasonal occurrence of Tetranychus urticae Koch in relation to Amblyseius addoensis van der Merwe \& Ryke on vines in the Hex River Valley, 1986/87 season: $\mathrm{A}=$ Hylton; $\mathrm{B}=$ De Vlei; $\mathrm{C}=$ VORI Expt. Farm.
During 1987/88 the mite infestation again appeared at the beginning of February but was smaller [average 2 mites/leaf during its peak at the end of February (Fig. 2A)]. Thereafter the infestation dropped to a very low level to disappear at the end of March. The 1988/89 season showed no build-up of the carmine form of T. urticae (Fig. 3A).

Tetranychus urticae (carmine form) did not occur on bunches during the period of study, although Swart et al. (1976) do mention damage to bunches on late cultivars.

De Vlei: As shown in Fig. 1B, T. urticae was absent during the 1986/87 season; in fact an infestation of the mite (green form) had occurred at bud burst (prior to the inception of sampling) and was successfully controlled with an acaricide spray applied by the producer. During the next season $(1987 / 88)$ the infestation again commenced at bud burst, with the mite moving from infested weeds in the vineyard onto the vines (Fig. 2B). According to Schruft, Mittenmuller \& Stark (1979) $T$. urticae is fully active on green underlying growth long before vine sprouting in Kaiserstuhl, German Federal Republic. A Peak (average 43 mites/leaf) was recorded on 23rd October. Thereafter, the infestation dwindled rapidly to low numbers at the beginning of December and remained

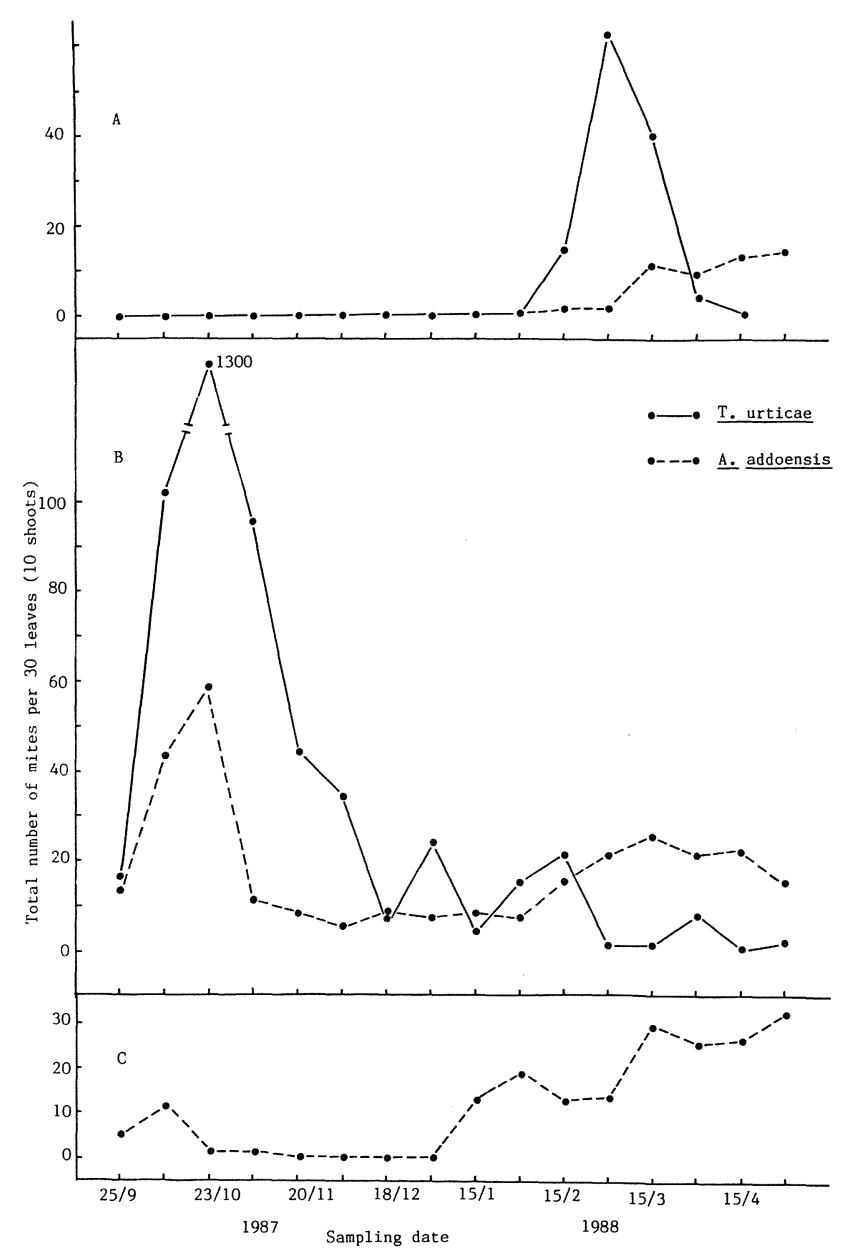

FIGURE 2

The seasonal occurrence of Tetranychus urticae Koch in relation to Amblyseius addoensis van der Merwe \& Ryke on vines in the Hex River Valley, 1987/88 season: A = Hylton; $\mathrm{B}=$ De Vlei; $\mathrm{C}=$ VORI Expt. Farm. 


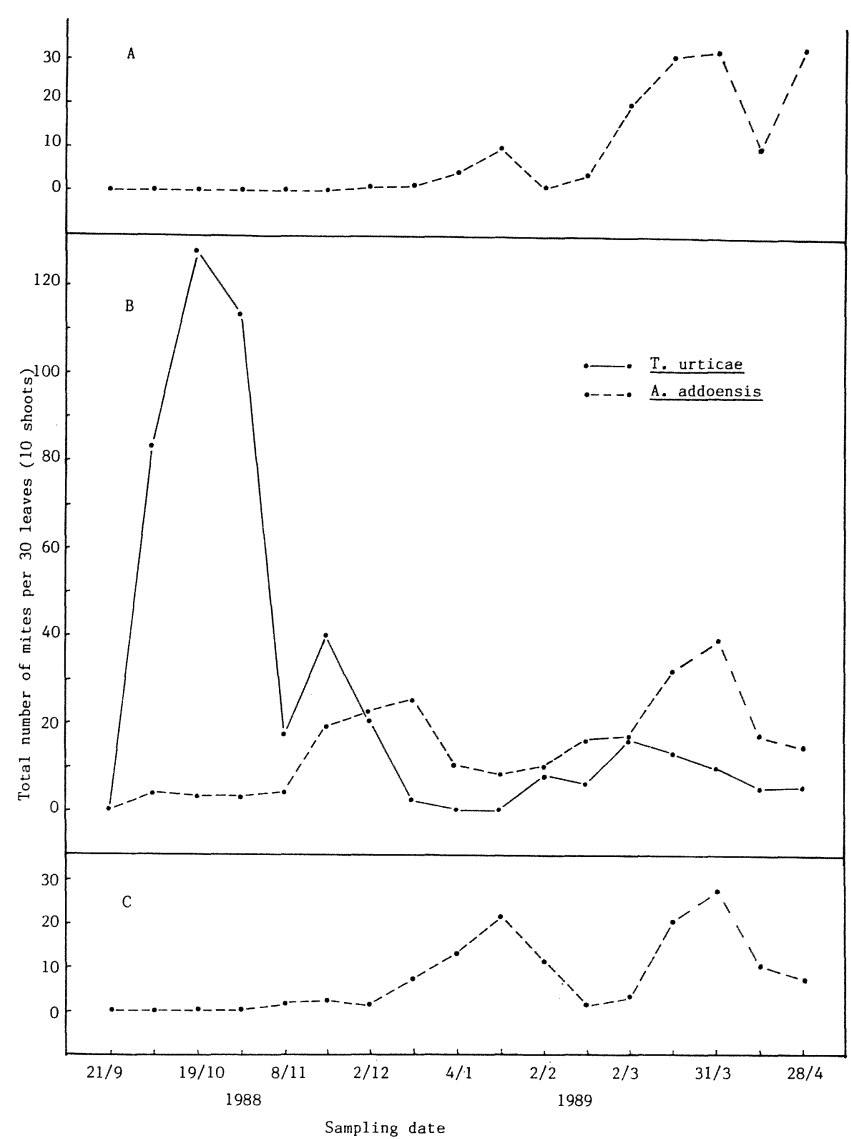

FIGURE 3

The seasonal occurrence of Tetranychus urticae Koch in relation to Amblyseius addoensis van der Merwe \& Ryke on vines in the Hex River Valley, 1988/89 season: A = Hylton; $\mathrm{B}=$ De Vlei; $\mathrm{C}=$ VORI Expt. Farm. such for the duration of the season (Fig. 2B).

During the 1988/89 season, as during the previous season, the vineyard again became infested with the green form of the mite at the bud burst stage, with a population peak on 19th October 1988 (average, 4 mites/leaf) (Fig. 3B). Three weeks later the mite population had dropped to a low level, which was maintained for the rest of the season.

The mites did not infest the bunches. It is noteworthy that weed control in the vineyard had been improperly carried out during the period of study.

VORI Experimental farm: Tetranychus urticae was absent from the Barlinka vineyard during the three seasons of study (Figs. 1C, 2C \& 3C).

The infestation of $T$. urticae relative to leaf position on a shoot: According to Fig. 4 the carmine form of $T$. urticae exhibited a preference for the older basal leaves on a shoot, followed by the middle-position leaves during the 1987 infestation. The sampling of positional leaves on a shoot during the height of an infestation indicated that young leaves were preferred by the green form (data not shown). Both forms of T. urticae fed mainly on the underside of leaves.

Damage by $T$. urticae: The early season infestation of Barlinka by the green form, as experienced at De Vlei, resulted in the margins of young leaves turning brown. Injured leaves remained small and deformed. When the infestation was heavy, injured leaves shrivelled and became desiccated. Feeding on mature leaves caused chlorosis.

Feeding by the carmine form on Almeria at Hylton led to chlorosis or the bronzing of especially the older leaves, which is similar to the effect observed by Swart et al. (1976) for the red coloured $T$. cinnabarinus (now $T$. urticae). Furthermore, in extreme cases feeding and web-spinning by the mite could render infested bunches unsightly and unsuitable for export.

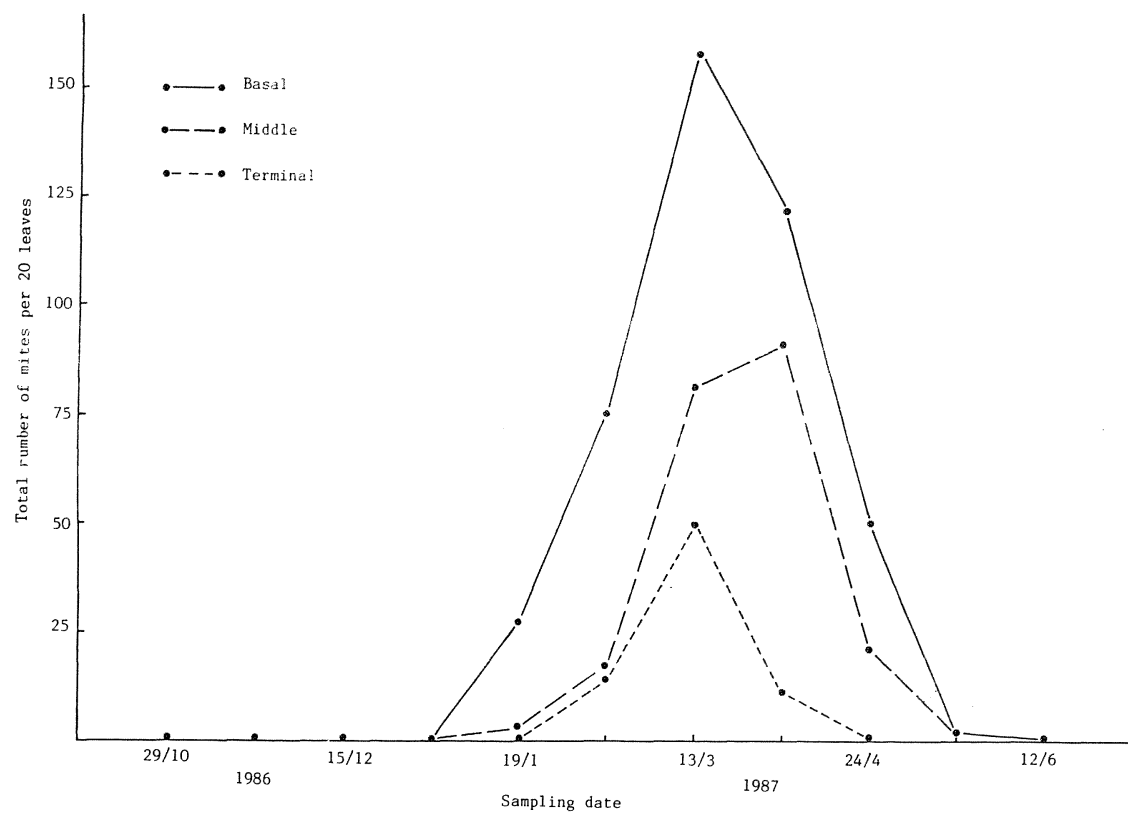

FIGURE 4

The distribution of Tetranychus urticae (carmine form) adults on positional leaves (Hylton). 


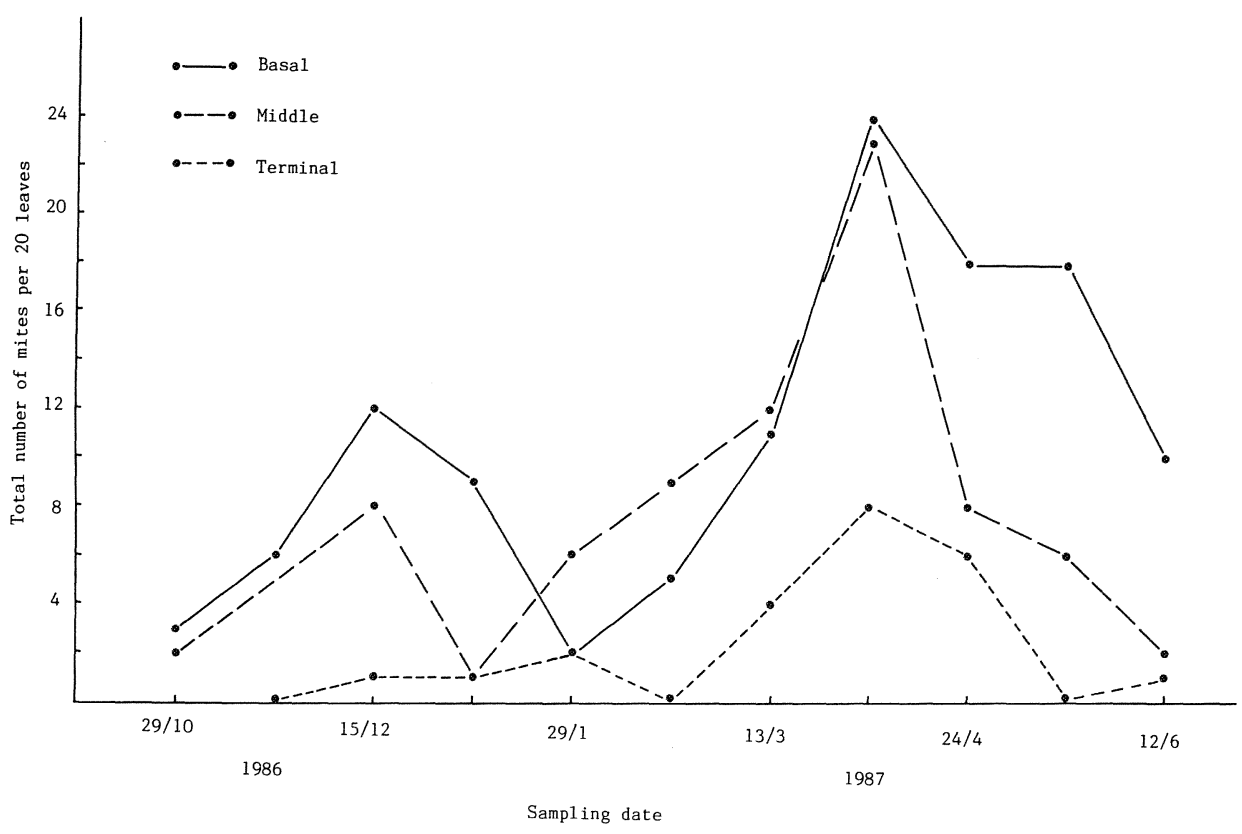

FIGURE 5

The distribution of the motile stages of Amblyseius addoensis van der Merwe \& Ryke on positional leaves (VORI Expt. farm).

This situation was not experienced during the present investigation.

Natural enemies: The only predaceous arthropod that occurred in appreciable numbers was the mite Amblyseius addoensis Van der Merwe \& Ryke. The importance of predaceous mites from the family Phytoseiidae as effective predators of the Tetranychidae is well documented (McMurtry, Huffaker \& Van De Vrie, 1970; Chant, 1985). Observations in the laboratory confirmed that A. addoensis preys on all stages of $T$. urticae.

The results in Fig. 5 show that $A$. addoensis was most prevalent on the basal leaves of Barlinka shoots, followed closely by the middle-position leaves during the season. The same pattern was evident in the vineyards of De Vlei and Hylton (data not shown). This distribution characteristic is similar to that of the carmine form of T. urticae (Fig. 4), which is one of the requirements for a good predator. Although not numerous, A. addoensis was also present on the young shoots of Barlinka at De Vlei during the early season infestation of the green form on such shoots (Fig. 2B). This phenomenon demonstrates the adaptability of the predaceous mite.

The influence of insecticidal spray programmes on the incidence of $T$. urticae and $A$. addoensis: The first two seasons of study (1986/87 and 1987/88) on Almeria at Hylton farm were characterised by an infestation of $T$. urticae (carmine form) during which the predaceous mite A. addoensis was scarcer than on the other two farms (Figs. $1 \& 2$ ). For the $1988 / 89$ season the number of organophosphate sprays was reduced and a pyrethroid treatment omitted; a sticky trunk barrier was applied as a substitute to control the banded fruit weevil. The outcome was the disappearance of $T$. urticae and a reasonable presence of $A$. addoensis (Fig. 3A).
Severe infestations of T. urticae (green form) were present during October of 1987 and 1988 on Barlinka at De Vlei (Figs. 2B \& 3B). These had developed at bud burst soon after a chlorpyrifos spray for the control of vine mealybug. The sampling of weeds in the vineyard prior to this spray had indicated the presence of both $T$. urticae and A. addoensis.

It is suggested that the chlorpyrifos spray was detrimental to the A. addoensis population on weeds (the control of which had been neglected) without affecting $T$. urticae, with a subsequent population explosion of the latter species in the relative absence of its predator. Laboratory tests have confirmed that chlorpyrifos and the pyrethroid insecticides were extremely toxic to A. addoensis (data not shown). The work of Englert \& Kettner (1983) attests to the harmful effect of organophosphates and synthetic pyrethroids on Typhlodromus pyri Scheuten, a beneficial phytoseiid which preys on T. urticae in vineyards of the German Federal Republic. Hoyt et al. (1979) found the use of permethrin in a grape-pest management programme in California unacceptable because of its toxicity to several important predators.

Amblyseius addoensis was most abundant and T. urticae absent where insecticide sprays were withheld (Barlinka, VORI Experimental farm, Figs. 1C, 2C \& 3C). Moreover, vine mealybug never got out of hand, which points to the successful biocontrol of this major insect pest as well.

The obvious explanation for the outbreaks of T. urticae following the insecticide spray applications appears to be the destruction of its natural enemy, A. addoensis. Although this seems to be the principal reason, other insecticide-related factors as well as poor weed control could also be involved. A major factor in some instances may be a stimulation of $T$. urticae reproduction by the insecticides, acting either directly on the mite or indirectly by altering host plant physiology 
(Fleschner, 1952; Jones \& Parrella, 1984). Laboratory investigations with dichlorfos and a pyrethroid on $T$. urticae under controlled conditions failed to validate the above hypothesis (data not shown). The possibility of stimulation effect should not be ruled out however, since insecticide application in a vineyard occurs under a wide range of environmental influences, host plant responses and application techniques, compared to static conditions in the laboratory. Moreover, McMurtry et al. (1970) warned that results in the laboratory may not provide a clear prediction of field results.

\section{CONCLUSIONS}

Both colour forms of $T$. urticae occur on different cultivars in the Hex River Valley, viz. an early form referred to as the green form, and a late form termed the carmine form.

The green form of the mite was more abundant on young leaves, with maximum numbers recorded in October: young leaves dried out to become brown or young shoots and leaves became stunted. It also caused chlorosis on mature leaves. The bronzing or chlorosis of mature leaves was caused by the carmine form, with infestations peaking in February or March.

Tetranychus urticae on table grapes in the Hex River Valley is obviously a candidate for biocontrol, provided that the organophosphate and pyrethroid insecticide treatments can be reduced or eliminated. These insecticides are necessary to control two of the most important insect pests of table grapes, viz. vine mealybug and banded fruit weevil. During the study a sticky trunk band was successfully substituted for pyrethroid treatment. Through regular vineyard inspections the satisfactory biocontrol of vine mealybug was achieved in some instances in the absence of an organophosphate insecticide. Future research will be directed towards finding alternative methods and/or selective chemicals to replace the broad-spectrum insecticides necessary for the control of key pests on table grapes.

\section{LITERATURE CITED}

BOTHA, J.H., 1989. Common red spider mite Tetranychus urticae (Acari: Tetranychidae) shows its true colours after acaricidal application. Proc. of Seventh Entomological Congress, Pietermaritzburg. 10th-13th July.

CHANT, D.A., 1985. The Phytoseiidae. In: HELLE, W. \& SABELIS, M.W. (eds.) Spider mites; their biology, natural enemies and control. Vol. 1B, Elsevier, New York.

ENGLERT, W.D. \& KETTNER, J., 1983. Nebenwirkungen von Pflanzenbehandlungsmitteln auf Spinnmilben und Raubmilben. Mit. dtsch. Ges. allg. angew. Ent. 4, 89-91.

FLESCHNER, C.A., 1952. Host-plant resistance as a factor influencing population density of citrus red mite on orchard trees. J. Econ. Ent. 45, 687-695.

HOYT, M.A., FLAHERTY, D., PEACOCK, W. \& CULVER, D., 1979. Vineyard and laboratory evaluations of methomyl, dimethoate and permethrin for a grape pest management program in the San Joaquin Valley of California. J. Econ. Ent. 72, 250-255.

JONES, V.P. \& PARRELLA, M.P., 1984. Greenhouse and laboratory studies on the sub-lethal effects of selected insecticides on Panonychus citri (McGregor). Can. Entomol. 116, 1033-1040.

McMURTRY, J.A., HUFFAKER, C.B. \& VAN DE VRIE, M., 1970. Ecology of Tetranychid mites and their natural enemies: A Review. Hildardia 40,331-458.

MEYER, MAGDALENA, K.P. (SMITH), 1987. African Tetranychidae (Acari: Prostigmata); with reference to the world genera. Entomology Mem. Dep. agric. tech. Serv. Repub. S. Afr. 69, 1-175.

SCHRUFT, G., MITTENMULLER, K. \& STARK, O.J., 1979. Die Überwinterung der Gemeinen Spinnmilbe Tetranychus urticae Koch an der Rebe und ihr Auftreten im Frühjahr. Wein-Wiss 34, 55-60.

SCHWARTZ, A., 1987. Seasonal occurrence of a predaceous mite. Amblyseius addoensis Van der Merwe \& Ryke (Acari: Phytoseiidae) on table grapes. S. Afr. J. Enol. Vitic. 8, 78-79.

SWART, P.L., BARNES, B.N. \& MYBURGH, A.C., 1976. Pests of table grapes in the Western Cape. Decid. Fruit Grow. 26, 1-22. 